\title{
The evolution of the Marie Stopes electrocautery no-scalpel vasectomy procedure
}

Timothy Black, CBE, MRCP, MFF, Chief Executive, Marie Stopes International, London, UK; Colin Francome, MA, PhD, Professor of Sociology of Health, Middlesex University, London, UK, and Editor of the Middlesex University Press Health Series

Correspondence: Timothy Black, Chief Executive, Marie Stopes International, 153-157 Cleveland Street, London W1T 6QW, UK

(Accepted $9^{\text {th }}$ May 2002)

The Journal of Family Planning and Reproductive Health Care 2002: 28(3): 137-138

\begin{abstract}
Objective. To review the evolution of the procedure, the reoperation rate and efficacy data for vasectomies performed in Marie Stopes centres during the periods 1990-1994 and 1995-1999.

Design. Retrospective review of re-operation rates and primary and secondary failures during the periods 1990-1994 and 1995-1999.

Setting. Marie Stopes vasectomy centres in the UK. Participants. A total of 41123 men undergoing vasectomy. Results. The re-operation rate for the period 1990-1994 was $0.7 \%$ and fell to $0.46 \%$ for $1995-1999$. The reported pregnancy rate fell from 1 in 1429 procedures for the period 1990-1994 to 1 in 2804 for 1995-1999.

Conclusion. The results show that vasectomy has had a low failure rate well below that of other methods of birth control. The outcome data continue to improve over time with the evolution of improved techniques and surgical expertise.
\end{abstract}

\section{Key message point}

- The pregnancy rate using electrocautery for vasectomy was 1 per 2804 procedures for the 4-year period 1995-1999.

\section{Introduction}

Vasectomy has been free on the National Health Service (NHS) since 1972 and provision has been supplemented by private practitioners and charitable organisations. According to Hospital Episode Statistics there were 48203 female and 35609 male sterilisation procedures performed in the NHS in 1998/1999. ${ }^{1}$ In some age groups there are more men who have been sterilised than women. In 1998, $19 \%$ of men in the 45-49 years age group had been sterilised compared to $15 \%$ of women, although women were more likely to have had another operation which rendered them sterile. ${ }^{2}$ Britain is one of only four countries, together with Bhutan, New Zealand and The Netherlands, with more sterilised men than women. ${ }^{3}$

\section{Launch of the Marie Stopes programme}

Dr Marie Stopes opened Britain's first family planning clinic in 1921. Four years later she established the world's first full private family planning centre in Whitfield Street, London, UK, which has been offering services continuously for the last 76 years.

Following the death of Dr Stopes in 1958, vasectomy was added to the contraceptive menu following a successful campaign to promote this procedure by the Simon Population Trust in $1966 .{ }^{4}$ In 1976 , when the centre came under new management, the service philosophy was changed from a patient to a customer orientation and vasectomy was actively marketed. A national, small, space advertising campaign using the theme 'a safe, simple, 5- minute, stop babies operation, available without fuss or waiting lists', was launched in male readership magazines and local press. Operating days were changed to Fridays and Saturdays in line with client preference. A comprehensive pre-tested 'Print Counselling' pack for mailing to enquirers was developed. The pre-operative doctor's examination was discontinued in favour of 'sameday' counselling using trained lay counsellors. The mandatory partner's consent was made optional. The traditional surgeon's cap and mask were discarded and the operating environment made less surgical and intimidating.

Responses to the advertising campaign highlighted many areas of 'unmet need', prompting the launch in 1978 of the first of a nationwide network of Marie Stopes satellite vasectomy centres. Interested general practitioners (GPs) with suitable premises were recruited, trained and equipped. A central call centre was established to handle client contacts. Apart from attendance for same-day counselling and operation all customer contacts were by phone and post - including post-operative sperm tests returned at 12 and 14 weeks. The client-centred programme was, and still is, essentially a 'mail order' vasectomy service. By the mid1980 s there were 18 Stopes vasectomy centres and in 2000 some 25 centres throughout England and Wales.

\section{Evolution of the Marie Stopes procedure}

The vasectomy technique practised by the doctors at the Marie Stopes centre from the mid-1960s to 1978 was the conventional local anaesthetic, two-incision 'cut and tie' ligature procedure. 5

In June 1978, Stanwood Schmidt described the lower complication and failure rates associated with reliance on electrocoagulation and reliant on subsequent fibrosis to occlude the vasa. ${ }^{6}$ A model 732 Birtcher Hyfrecator was purchased and the technique adopted. Under local anaesthesia the exposed vasa were divided and $5 \mathrm{~mm}$ of the urethral and $5 \mathrm{~mm}$ on the testicular sides coagulated. The sheath of the vas was then interposed between the vas ends and the skin sutured.

Initial experience confirmed Schmidt's reported reduced incidence of wound infections $(1.3 \%)$, haematomas $(0.4 \%)$ and lower incidence of sperm granulomas $(0.4 \%)$ and congestive epididymitis $(2.8 \%)$. However, a nil failure rate was never achieved. By 1979, over 400 vasectomies a month were being performed and a number of small innovations aimed at simplifying the procedure were tested and introduced. Pre-operation shaving of the scrotum was dropped, and a small, single, vertical scrotal incision adopted for which skin sutures were unnecessary. The technique of occluding the vasa was also modified. Vasectomy forceps comparable to a single-toothed Allis forceps developed by Dr Soonawala in India were imported for mobilising and teasing out a loop of vas. A centimetre either side of the loop was electrocoagulated intraluminarily. The 'Solid State' Birtcher Hyfrecator 
(Model 733 and subsequent models) was introduced in the mid-1980s and found to have inferior coagulation characteristics. Because of this Schmidt recommended that the lumen was destroyed by external diathermy with care being taken to leave a sliver of live muscle to serve as a source of fibroblasts. 6 Following the adoption of more extensive coagulation, fascial interposition, the value of which had been questioned, was successfully discontinued. ${ }^{7}$ Trials of an incisionless percutaneous electrocoagulation technique proved to be popular with clients but had an unacceptable re-operation rate $(7.8 \%){ }^{8}$

\section{The Marie Stopes procedure}

The Stopes vasectomy electrocoagulation vasa occlusion technique evolved in 1979 has, with the minor modifications described, been used in over 81000 vasectomies at Marie Stopes centres during the past 21 years. It is essentially a no-touch procedure, performed without premedication, using local anaesthesia, in a clinically clean setting. The scrotum is swabbed with Hibiscrub (chlorhexidine gluconate). The right vas is identified and isolated beneath the surface of the scrotum. The dermis and around the vas is infiltrated with lignocaine $1 \%$ or $2 \%$ with $1: 200000$ adrenaline using a 25-gauge needle. A small 5-7 $\mathrm{mm}$ vertical scrotal incision in any convenient avascular location is made with a number 15 or 11 scalpel blade through which the right vas is grasped and teased into a loop with a Soonawala forceps. A Birtcher 716 re-usable needle is used to coagulate the vasa as described using a Hyfrecator (now manufactured by ConMed Corporation) for monopolar electrocoagulation. The vas is then released and the procedure repeated on the left side through the same incision. Small bleeders in the sheath and superficial tissues are coagulated and a bulky dressing applied and held in place by tight underpants. The client is requested to sit in the waiting room for 20 minutes and to keep the wound dry for as long as possible. He is advised to mail in his sperm tests in the special containers provided at 12 and 14 weeks, and is instructed to use another form of contraception until given the 'all clear' following two consecutive azoospermic tests.

\section{Method}

The study was a retrospective review of repeated primary failures (where semen analysis post-vasectomy continues to show sperm) and secondary failures (where sperm reappear in the semen analysis at a later stage) of vasectomies performed at Marie Stopes centres during the period 1990-1999. The study period was further subdivided into two periods covering 1990-1994 and 1995-1999.

\section{Results}

The 10-year vasectomy experience, the number of centres, operating doctors, re-operations and reported pregnancies are shown in Table 1. A total of 45123 vasectomies were carried out during this decade. Of these $7.3 \%$ defaulted on their sperm tests. The mid-decade average number of sperm tests per client was $2.47 ; 49 \%$ required two tests and $21 \%$ three to four tests. Of the men declining the re-operation recommended after four unsatisfactory tests, $4 \%$ had eight or more tests before achieving azoospermia.

There were 13 reported pregnancies among partners of vasectomised men who had completed their tests and been sent the 'all clear' letter; a reported secondary failure rate of $0.04 \%$ or 1 per 2500 vasectomies. Over the course of the decade there was a slight improvement in the recorded primary and secondary failure rates. The re-operation rate for the period $1990-1994$ was $0.7 \%$ and $0.46 \%$ over the following 5 years. The reported pregnancy rate fell from 1 in 1429 procedures to 1 in 2804 .

\section{Discussion}

The Marie Stopes organisation use of electrocautery to occlude the vasa without fascial interpositioning in 81000 cases confirms the Elliot Smith Clinic series of 12300 diathermy cases that this is a quick, safe, simple and effective vasectomy technique. ${ }^{9}$ The primary failure rate resulting in a re-operation because of continuing presence of sperm of $0.64 \%$ is comparable to the Elliot Smith Clinic incidence of $0.7 \%$ and that achieved by surgeons at the Margaret Pyke Centre using the cut and tie technique in the early $1970 \mathrm{~s}(0.6 \%)^{5}$

\section{Conclusion}

The results of this study show that vasectomy has had a low failure rate, which is well below that of other methods of birth control. The lower failure rate in the second of the two 5 -year periods is welcome, however, the surgeons concerned would like to be able to eliminate all failures.

Statements on funding and competing interests

Funding. None declared.

Competing interests. Dr Black is Chief Executive of Marie Stopes International. Professor Francome has no financial relationship with Marie Stopes International.

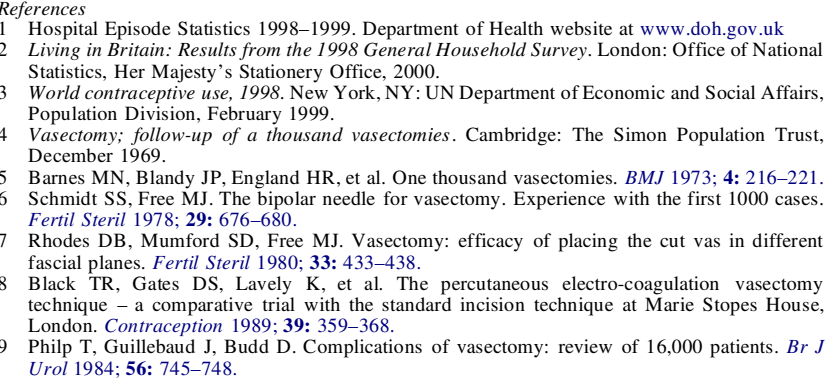

Philp T, Guillebaud J, Budd D. Complications of vasectomy: review of 16,000 patients. $\mathrm{Br} J$ Urol 1984; 56: 745-748.

Table 1 Marie Stopes vasectomies: primary and secondary failures 1990-1999

\begin{tabular}{|c|c|c|c|c|c|c|c|c|c|}
\hline \multirow[t]{2}{*}{ Year } & \multirow[t]{2}{*}{ Centres } & \multirow{2}{*}{$\begin{array}{l}\text { Operating } \\
\text { doctors }\end{array}$} & \multirow[t]{2}{*}{ Vasectomies } & \multicolumn{2}{|c|}{ Test defaulters } & \multirow[t]{2}{*}{ Re-operations } & \multirow{2}{*}{$\begin{array}{l}\text { Men tested } \\
(\%)\end{array}$} & \multirow{2}{*}{$\begin{array}{l}\text { Reported } \\
\text { pregnancies }\end{array}$} & \multirow{2}{*}{$\begin{array}{l}\text { Vasectomies } \\
(\%)\end{array}$} \\
\hline & & & & $\mathrm{n}$ & $\%$ & & & & \\
\hline 1990 & 22 & 25 & 4062 & 334 & 8.22 & 16 & 0.43 & 1 & 0.02 \\
\hline 1991 & 22 & 25 & 3738 & 298 & 7.92 & 29 & 0.84 & 2 & 0.05 \\
\hline 1992 & 23 & 26 & 3683 & 292 & 7.93 & 27 & 0.8 & 1 & 0.02 \\
\hline 1993 & 21 & 24 & 4058 & 278 & 6.85 & 20 & 0.53 & 0 & - \\
\hline 1994 & 21 & 24 & 4347 & 263 & 6.05 & 22 & 0.54 & 2 & 0.05 \\
\hline 1995 & 25 & 28 & 4683 & 390 & 8.33 & 12 & 0.28 & 2 & 0.04 \\
\hline 1996 & 24 & 27 & 4749 & 389 & 8.19 & 25 & 0.57 & 4 & 0.08 \\
\hline 1997 & 26 & 30 & 5344 & 289 & 5.4 & 66 & 1.3 & 1 & 0.02 \\
\hline 1998 & 25 & 29 & 5576 & 359 & 6.44 & 23 & 0.44 & 2 & 0.04 \\
\hline 1999 & 25 & 29 & 4883 & 417 & 8.54 & 27 & 0.6 & 0 & - \\
\hline Totals & & & 45123 & 3309 & 7.3 & 267 & 0.64 & 15 & 0.03 \\
\hline
\end{tabular}

